\title{
Engineering eukaryotic protein factories
}

\author{
Martin Schröder
}

Received: 28 August 2007/ Accepted: 30 August 2007 / Published online: 21 September 2007

(C) Springer Science+Business Media B.V. 2007

\begin{abstract}
The biopharmaceuticals market is currently outperforming the pharmaceuticals market and is now valued at US\$ 48 billion with an average annual growth of $19 \%$. Behind this success is a 100 fold increase in productivities of eukaryotic expression systems. However, the productivity per cell has remained unchanged for more than 10 years. The engineering of the ER-resident protein folding machinery is discussed together with an overview of signal transduction pathways activated by heterologous protein overexpression to increase cell specific productivities.
\end{abstract}

\section{Keywords}

Endoplasmic reticulum associated protein degradation - Heterologous protein production . Molecular chaperone - Protein folding . Unfolded protein response

\section{Introduction}

The demand for therapeutic proteins, i.e. monoclonal antibodies, has been forecast to exceed production capacities (Werner 2004). Moderate increases in product titers and yields are expected to result in

M. Schröder $(\square)$

School of Biological and Biomedical Sciences, Durham University, South Road, Durham DH1 3LE, UK

e-mail: martin.schroeder@durham.ac.uk significant savings in capital investment and consumer costs (Werner 2004). Over the last decade product titers have increased from $\sim 20 \mathrm{mg} \mathrm{l}^{-1}$ to $2 \mathrm{~g} \mathrm{l}^{-1}$ (Werner 2004; Wurm 2004). These improvements are largely attributable to increases in viable cell densities. However, cell specific productivities remained nearly constant during this time (Wurm 2004).

To improve cell specific productivities the bottleneck for heterologous protein secretion has to be identified and resolved. In expression systems exploiting multiple gene copies or strong promoters the amount of secreted heterologous protein does not increase proportionally with gene copy number (Schröder 2007), messenger ribonucleic acid (mRNA) (Schröder et al. 1999), or even the intracellular amount of the heterologous protein (Schröder and Friedl 1997). In these cells, the protein accumulates in intracellular aggregates (Schröder and Kaufman 2005), associates with the molecular chaperone heavy chain-binding protein $(\mathrm{BiP}) /$ glucoseregulated protein of $78 \mathrm{kDa}$ (GRP78)/karyogamy 2 protein (Kar2p) (Schröder and Kaufman 2005), and induces dilation of the endoplasmic reticulum (ER) (Dorner et al. 1989; Gennaro et al. 1991). Therefore, exit of the correctly folded polypeptide chain from the ER is the rate-limiting step for heterologous protein secretion. I will discuss strategies to improve cell specific productivities by engineering protein folding in the ER and signal transduction pathways activated by overexpression of heterologous proteins. 


\section{Protein folding in the ER}

The ER-resident protein folding machinery has four components: (1) Molecular chaperones assisting other proteins to fold, (2) enzymes such as protein disulfide isomerases (PDIs) and cis-trans peptidyl prolyl isomerases (PPIs), (3) a degradation machinery, and (4) signal transduction pathways that coordinate protein folding demand with capacity. At least three hierarchically organized chaperone systems operate in the ER, the heat shock protein of $70 \mathrm{kDa}$ (HSP70) chaperones BiP and luminal HSP seventy 1 protein $($ Lhs $1 \mathrm{p}) /$ chaperone in the ER 1 protein/Ssi1p/GRP170/oxygen-regulated protein of $150 \mathrm{kDa}$ (ORP150), the HSP90 chaperone GRP94/ adenotin/endoplasmin/tumor rejection antigen glycoprotein of $96 \mathrm{kDa}$ (gp96)/ER protein of $99 \mathrm{kDa} /$ $\mathrm{HSP} 108 / \mathrm{Ca}^{2+}$-binding protein 4/protein kinase of $80 \mathrm{kDa}$, and the lectin chaperones calnexin/p88, calreticulin/ $/ \mathrm{Ca}^{2+}$-binding protein of $63 \mathrm{kDa}(\mathrm{CAB}-$ $63) /$ calregulin $/ \mathrm{Ca}^{2+}$-regulated protein of $55 \mathrm{kDa}$ (CRP55)/high affinity $\mathrm{Ca}^{2+}$-binding protein (HA$\mathrm{CBP}$ ), and calmegin/calnexin-t (Fig. 1). BiP works

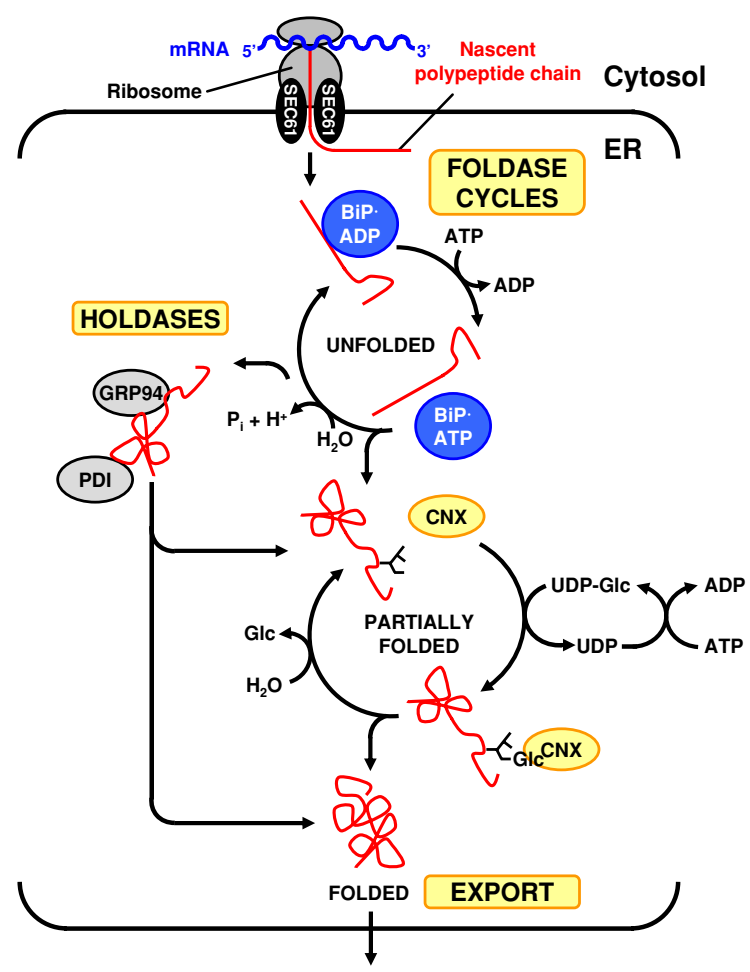

Fig. 1 Hierarchy of chaperone systems in the ER. Abbreviations: Glc $=$ D-glucose, $\mathrm{P}_{\mathrm{i}}=$ inorganic phosphate $\left(\mathrm{HPO}_{4}^{2-}\right)$ on completely unfolded polypeptide chains and translocates nascent polypeptide chains into the ER, whereas GRP94 and the lectin chaperones work on partially folded substrates.

BiP consists of an $N$-terminal ATPase domain and a $C$-terminal substrate binding domain. BiP cycles through rounds of adenosine triphosphate (ATP) hydrolysis and adenosine diphosphate (ADP) ATP exchange (Fig. 1), which makes BiP a chaperone foldase (Winter and Jakob 2004). At least six DnaJ or HSP40 co-chaperones stimulate the ATPase activity of $\mathrm{BiP}$ and two growth after phage induction $\mathrm{E}$ (GrpE) co-chaperones the ADP ATP exchange reaction. In the ADP-bound form BiP has high affinity for unfolded substrates. Substrates bound to BiP are conformationally locked. ADP ATP exchange decreases the affinity of $\mathrm{BiP}$ for unfolded substrates. Substrate binding stimulates the ATPase activity of BiP. Thus, protein folding requires ATP (Dorner and Kaufman 1990). BiP and Lhs1p coordinate their activities. Lhs1p is a nucleotide exchange factor for $\mathrm{BiP}$, and BiP stimulates the ATPase activity of Lhs1p (Steel et al. 2004).

Cytosolic HSP90 chaperones are ATP-consuming chaperone foldases (Fig. 1) regulated by several cochaperones that affect its ATPase activity, load substrates onto HSP90 chaperones, assist in protein folding, and target substrates to degradation pathways (Strudwick and Schröder 2007). GRP94 co-chaperones have not been identified, but other ER luminal chaperones found in complexes with GRP94 may be GRP94 co-chaperones. The $K_{\mathrm{M}}$ value of GRP94 for ATP is $\sim 100 \mu \mathrm{M}$ and its intrinsic ATPase activity is barely detectable. These data indicate that GRP94 may be a chaperone holdase, a chaperone that binds to unfolded proteins, but does not cycle through ATP hydrolysis cycles. A drop of adenine nucleoside concentrations in stress situations may activate GRP94 (Rosser et al. 2004).

The lectin chaperones share an $\mathrm{N}$-terminal globular oligosaccharide-binding domain and a $C$-terminal extended hairpin loop, the $\mathrm{P}$ domain, which provides the chaperone function (Strudwick and Schröder 2007). Calnexin and calmegin are transmembrane proteins. Calreticulin is a soluble protein. Most proteins entering the ER are glycosylated by addition of the oligosaccharide $\mathrm{Glc}_{3} \mathrm{Man}_{9} \mathrm{GlcNAc}_{2}(\mathrm{Glc}=\mathrm{D}-$ glucose, Man = D-mannose, GlcNAc $=N$-Acetyl-2D-glucosamine). $\alpha$-Glucosidases I and II rapidly 
remove the two terminal D-glucose residues. Calnexin and calreticulin bind to this monoglucosylated oligosaccharide. Removal of the third D-glucose moiety by $\alpha$-glucosidase II releases the protein from calnexin/ calreticulin. Reglucosylation of unfolded proteins by uridine diphosphate (UDP)-glucose:glycoprotein glucosyl transferase (UGGT) triggers repeated interactions with calnexin/calreticulin (Fig. 1). This reglucosylation reaction consumes UDP-glucose. Therefore, the calnexin chaperones are chaperone foldases. The Saccharomyces cerevisiae genome encodes a calnexin homolog, but no homolog for UGGT, suggesting that the lectin chaperones may also function as holdases. Demannosylation of $\mathrm{N}$ linked oligosaccharides trigger export of proteins to the Golgi complex or their targeting for retrotranslocation into the cytosol and proteasomal degradation (Lederkremer and Glickman 2005; Ruddock and Molinari 2006).

An expanding family of PDIs catalyzes the formation and isomerization of disulfide bonds. Disulfide bond formation requires the regeneration of oxidized PDI catalyzed by the flavin adenine dinucleotide (FAD)-dependent oxidases ER oxidation 1 protein (Ero1p)/ERO1-L $\alpha$, ERO1-L $\beta$ and essential for respiration and viability 2 protein (Erv2p) (Fig. 2). The final electron acceptor is molecular oxygen. Oxidative protein folding accounts for $\sim 25 \%$ of all reactive oxygen species (ROS) formed in a cell (Tu and Weissman 2004) and is increased by ER stress (Haynes et al. 2004). Disulfide bond isomerization is independent of the Erolp oxidases. Reduced glutathione provides reducing equivalents to remove incorrectly formed disulfide bonds. PDI has chaperone holdase activity that is independent of its protein disulfide isomerase activity (Wilkinson and Gilbert 2004) and redox-regulated foldase activity (Tsai et al. 2001).

Slowly folding proteins or folded incompetent proteins have to be removed from chaperone cycles to prevent them from poisoning the protein folding machinery. This is achieved by targeting these proteins for retrotranslocation into the cytosol and degradation by the proteasome in a process called ER associated protein degradation (ERAD) (Yoshida 2007) (Fig. 3). Proteins destined for ERAD are recognized by BiP, PDI, and lectin sensors such as ER-degradation enhancing $\alpha$-mannosidase-like proteins 1-3 (EDEM1-3)/homologous to mannosidase I 1 protein $(\mathrm{Htm} 1 \mathrm{p}) /$ mannosidase-like 1 protein (Mnl1p) and osteosarcoma-9 (OS-9)/yeast OS-9 homolog protein (Yos9p) (Gauss et al. 2006a). The lectin sensor EDEM extracts unfolded proteins from the calnexin cycle. ERAD substrates are then
Fig. 2 Disulfide bond formation and isomerization reactions catalyzed by PDI

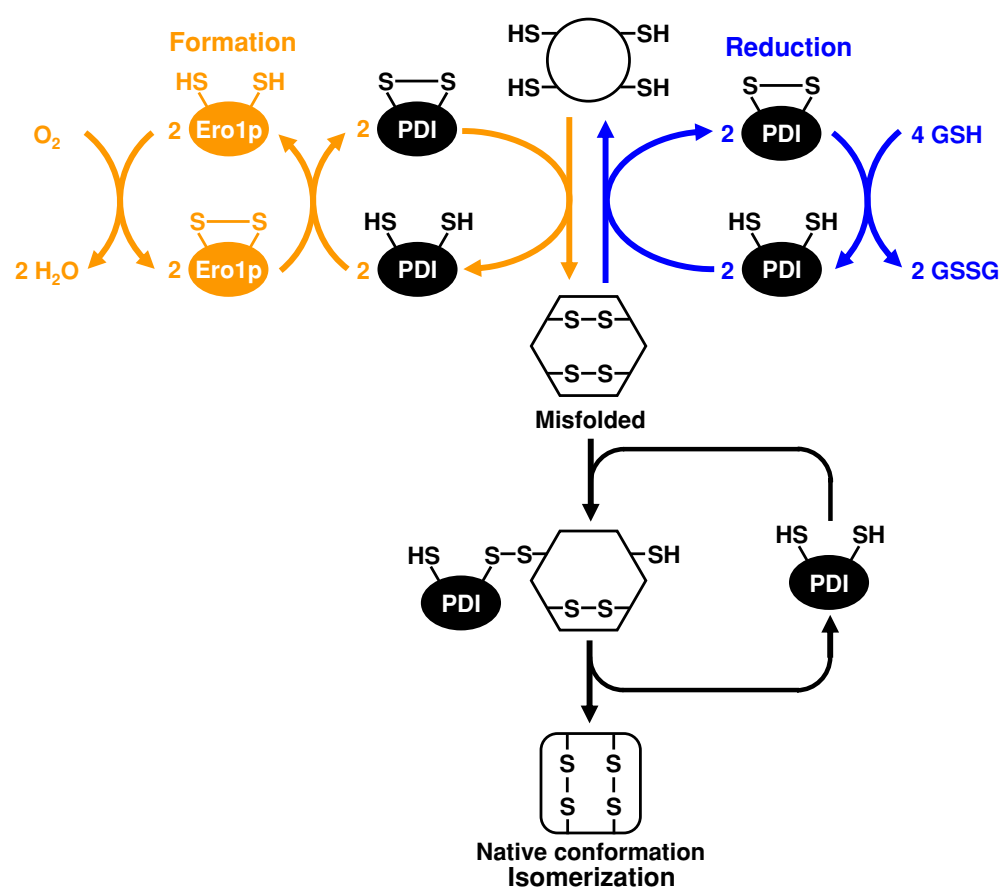



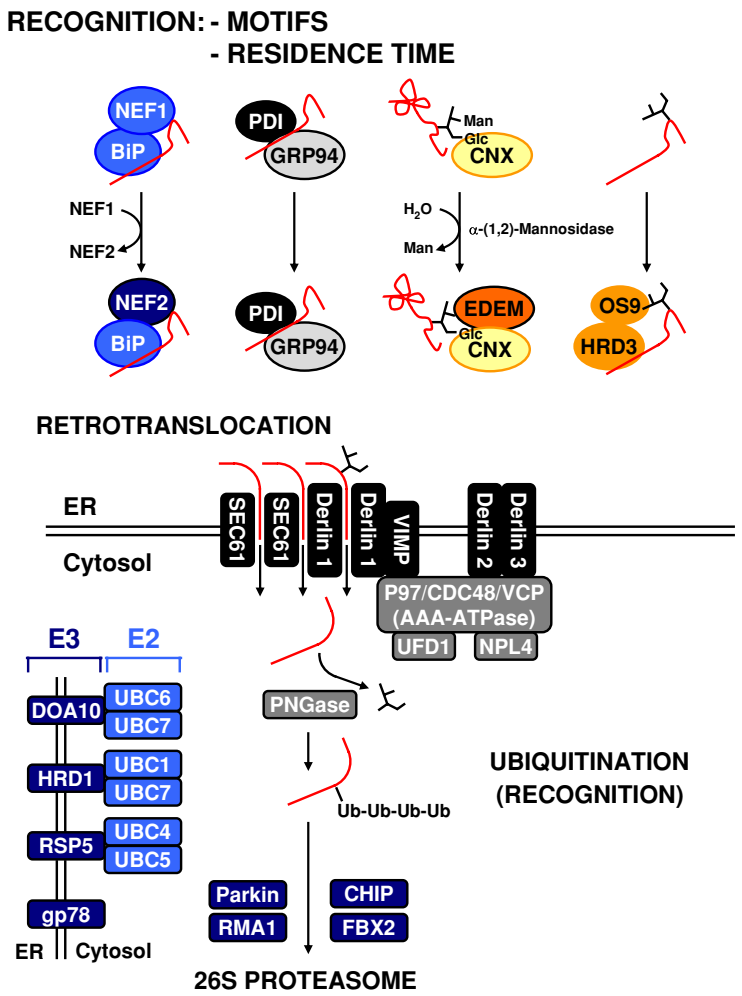

Fig. 3 ER associated protein degradation. The exact nature of the retrotranslocation channel is unknown. The list of E2 and E3 enzymes catalyzing ubiquitination of ERAD substrates is not exhaustive. Abbreviations: $\mathrm{NEF}=\mathrm{HSP} 70$ co-chaperone, $\mathrm{Ub}=$ ubiquitin

retrotranslocated into the cytosol via the secretory 61 (SEC61) channel or a channel formed by derlin proteins, ubiquitinated by action of ubiquitin-conjugating enzymes (E2 enzymes) and ubiquitin ligases (E3 enzymes), deglycosylated, and degraded by the proteasome. Redundancy exists in the ubiquitination machinery involved in ERAD. In yeast and mammalian cells at least three distinct E2.E3 complexes are present in the ER membrane. The substrate specificities of these complexes, as well as their substrate selection rules are poorly understood. In yeast, the E3 ligase Hrd1p co-operates with $\mathrm{Hrd3}$ p and Yos9p to select its substrates (Gauss et al. 2006b). Another selection criterion is the time an unfolded protein spends in foldase cycles. In the calnexin cycle, demannosylation of $\mathrm{N}$-linked oligosaccharides generates glycostructures recognized by lectins such as EDEM1-3. Association of cytosolic HSP70s with the nucleotide exchange factor $\mathrm{B}$ cell leukemia/lymphoma 2 (Bcl-2) associated athanogene protein 1
(BAG-1) (Alberti et al. 2003) and of cytosolic HSP90s with the ubiquitin ligase carboxyl terminus of heat shock cognate protein of $70 \mathrm{kDa}$ (HSC70) interacting protein (CHIP) (Höhfeld et al. 2001) targets proteins for proteasomal degradation. Association of the DnaJ co-chaperone $58 \mathrm{kDa}$ inhibitor of double-stranded RNA activated protein kinase (PKR, $\mathrm{p} 58^{\mathrm{IPK}}$ ) with HSP70 chaperones at the translocation pore targets proteins, whose translocation into the ER is stalled, for proteasomal degradation (Oyadomari et al. 2006). If similar targeting mechanisms for proteins folding slowly in the $\mathrm{BiP}$ foldase cycle exist, is currently unknown.

\section{Engineering of chaperone machineries}

Engineering of chaperone holdases should be straightforward. Holdases hold onto an unfolded protein and act in an equimolar ratio to the unfolded substrate, but are unable to support folding reactions. Holdases may provide a buffer capacity to prevent aggregation of unfolded proteins. Co-overexpression of chaperone foldases may be beneficial to overexpression of holdases (Smith et al. 2004; Zhang et al. 2006b). Overexpression data for calnexin/calreticulin and PDI are most easily explained by assuming that this buffer capacity is increased. Calnexin or calreticulin overexpression generally improved heterologous protein secretion (Chung et al. 2004; Conesa et al. 2002; Kato et al. 2005). Overexpression of one cycle constituent should not increase cycle capacity, if this constituent is not limiting, and if constituent levels are not co-regulated. The hypothesis that calnexin or calreticulin are limiting for the calnexin cycle seems unlikely, because of the high abundance of these proteins. Alternatively, overexpression of calnexin or calreticulin may inactivate lectins such as EDEM (Molinari et al. 2003; Oda et al. 2003), which target unfolded proteins for ERAD. Further, elevated calnexin or calreticulin levels not supported by concomitant increases in activities of other calnexin cycle components, may convert these surplus amounts of calnexin and calnexin into holdases or inactive chaperones.

PDI overexpression increased secretion of some, but not all, heterologous proteins (Butz et al. 2003; Damasceno et al. 2006; Inan et al. 2006; Kato et al. 2005; Mohan et al. 2007; Schröder 2007; Zhang et al. 2006b). PDI overexpression provides increased 
holdase activity in the ER. For example, overexpression of catalytically inactive PDI improved heterologous protein secretion (Hayano et al. 1995). PDI overexpression also improved secretion of heterologous proteins containing no disulfide bonds (Powers and Robinson 2007; Smith et al. 2004; Vad et al. 2005). Substrate selectivity of PDI may explain why PDI overexpression failed to increase heterologous protein secretion in some studies (Butz et al. 2003; Damasceno et al. 2006; Mohan et al. 2007; Schröder 2007). If this is the case, co-expression of an alternative holdase, i.e. GRP94, may yield more consistent results for different heterologous proteins. Alternatively, increased rates of disulfide bond formation or isomerization in PDI overexpressing cells may explain increased heterologous protein secretion. As an enzyme, PDI should function at substochiometric ratios to its substrates. In disulfide bond formation, regeneration of oxidized PDI may become rate-limiting in PDI overexpressing cells. PDI is an abundant ER protein, making it unlikely that its overexpression can significantly augment its catalytic activities.

Engineering of foldases seems more difficult, because of the complex regulation of these chaperones (see above). BiP overexpression increased heterologous protein secretion for about half of the heterologous proteins studied (Chung et al. 2004; Damasceno et al. 2006; Dorner et al. 1992; Hsu and Betenbaugh 1997; Kim et al. 2003; Schröder 2007; Smith and Robinson 2002; Zhang et al. 2006b), but can also have negative effects (Dorner et al. 1992; Schröder 2007). In cells overexpressing BiP one of its co-chaperones, Lhs1p, or ER luminal ATP may become limiting, converting $\mathrm{BiP}$ into a holdase or inactive chaperone. This may target proteins towards ERAD, stall translocation, convert Lhs1p into a holdase or inhibit Lhs1p. Increased BiP activity may stall the GRP94 and/or calnexin-calreticulin chaperone machineries, because of the hierarchy of ER luminal chaperone systems. This again may target heterologous proteins for ERAD. BiP overexpression attenuates the unfolded protein response (UPR, see below). Thus, BiP levels in $\mathrm{WT}$ and $\mathrm{BiP}$ overexpressing cells expressing a heterologous protein may not be dramatically different. Further, BiP overexpressing cells may experience an imbalance in their chaperone machineries, because the UPR co-ordinates expression of several chaperones. Moreover, if overexpression of $\mathrm{BiP}$ shifts the folding bottleneck to the GRP94 and calnexin chaperone systems, upregulation of these chaperone systems by the UPR may be blunted, because of suppression of UPR activation by elevated BiP levels.

\section{Unfolded protein response (UPR)}

ER stress is the perturbation of the balance between the folding capacity and the folding demand imposed on the ER. To restore ER homeostasis, the UPR activates expression of chaperone, PDI, PPI, and ERAD genes, attenuates transcription of genes encoding secretory proteins and general translation, induces phospholipid synthesis, and induces an inflammatory response. Apoptosis is induced if these actions fail to restore ER homeostasis or in response to prolonged ER stress (Schröder and Kaufman 2005).

The ER membrane of higher eukaryotes harbors at least three classes of transmembrane proteins activated by ER stress, basic leucine zipper (bZIP) transcription factors synthesized as type II transmembrane proteins, of which the best characterized are activating transcription factor $6 \alpha$ (ATF $6 \alpha$ ) and ATF6 $\beta /$ cyclic adenosine monophosphate response element binding protein (CREB)-related protein (CREB-RP)/G13, the protein kinase eukaryotic translation initiation factor $2 \alpha$ (eIF2 $\alpha)$ kinase 3 (EIF2AK3)/pancreatic eIF2 $\alpha$ kinase (PEK)/PKR-like ER kinase (PERK), and the protein kinase-endoribonucleases ER to nucleus signaling $1 \alpha(\mathrm{ERN} 1 \alpha) /$ inositol-requiring $1 \alpha$ (IRE1 $\alpha$ ) and IRE1 $\beta$ (Fig. 4). Several ATF6 paralogs, CREB3, CREB4, CREB-H, box $\mathrm{B}$ binding factor $2(\mathrm{BBF} 2)$, and old astrocyte specifically induced substance (OASIS) have recently been described. In unstressed cells, these stress sensors are bound to $\mathrm{BiP}$ and kept in an inactive state. Upon ER stress, BiP is released coinciding with their activation. Whether $\mathrm{BiP}$ release is triggered by sequestration by unfolded proteins, conformational changes in the ER luminal domains, or reactivation of the BiP ATPase cycle is currently being debated (Kimata et al. 2004; Shen et al. 2005). ER stress also alters interactions of pro- and antiapoptotic Bcl-2 proteins at the ER membrane. These proteins regulate ER luminal $\mathrm{Ca}^{2+}$ homeostasis, ER morphology, ER stress signaling, and apoptosis induced in response to ER stress (Hetz 2007). 
Fig. 4 Signal transduction pathway in the UPR. In the human UPR caspase 4 substitutes for caspase 12 . In yeast and filamentous fungi, the IRE1-XBP-1 (Hac1p/HACA) pathway is the only known UPR signal transduction pathway. [Reprinted in modified form with permission from Bentham Science Publishers from Schröder M, Kaufman, RJ (2006) Divergent roles of IRE1 $\alpha$ and PERK in the unfolded protein response. Curr Mol Med 6:5-36]

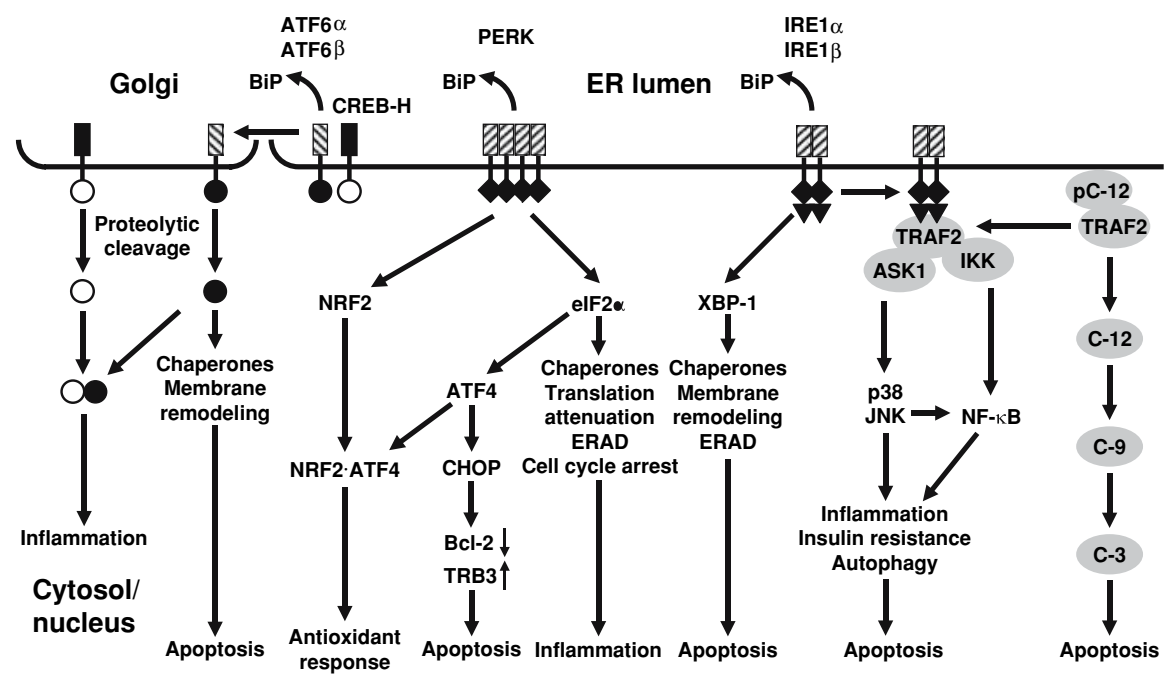

BiP release from ATF6 induces translocation of ATF6 to the Golgi complex where its bZIP transcription factor domain is proteolytically released from the Golgi membrane by site 1 and 2 proteases (S1P and S2P) (Fig. 4). This cytosolic fragment translocates to the nucleus and induces expression of chaperone genes (Strudwick and Schröder 2007). The functions of the ATF6 paralogs in the ER stress response is less well understood. OASIS contributes to activation of the $\mathrm{BiP}$ gene (Kondo et al. 2005), and ATF6.CREB-H heterodimers activate inflammatory genes (Zhang et al. 2006a).

BiP release from PERK triggers oligomerization and activation of the protein kinase domain of PERK. PERK phosphorylates the bZIP transcription factor nuclear factor erythroid 2 (NF-E2) related factor 2 (NRF2) and eIF2 $\alpha$ (Strudwick and Schröder 2007) (Fig. 4). NRF2 phosphorylation induces its translocation to the nucleus, where a NRF2.ATF4 heterodimer activates transcription of antioxidant response genes (Harding et al. 2003) to counteract ROS formation by repeated folding attempts of nascent polypeptide chains in ER stressed cells. eIF $2 \alpha$ phosphorylation attenuates general translation and decreases the influx of nascent unfolded polypeptide chains into the ER. It also clears short-lived proteins from the cell, i.e. D-type cyclins, resulting in cell cycle arrest in $\mathrm{G}_{1}$ phase, and of inhibitors of nuclear factor $\kappa \mathrm{B}(\mathrm{NF}-\kappa \mathrm{B})(\mathrm{I} \kappa \mathrm{B})$, activating the proinflammatory transcription factor NF- $\kappa \mathrm{B}$. eIF2 $\alpha$ phosphorylation also induces preferential translation of capped mRNAs containing several short upstream open reading frames (uORFs) and cap-independent translation of mRNA via internal ribosomal entry sites (IRES). Currently, the only known mRNA whose translation is stimulated by ER stress is the mRNA encoding the bZIP transcription factor ATF4. ATF4 induces expression of CCAAT enhancer binding protein $(\mathrm{C} / \mathrm{EBP})$ homologous protein $(\mathrm{CHOP}) /$ CHOP-10/growth arrest and DNA damage-inducible gene 153 (GADD153). CHOP represses transcription of anti-apoptotic BCL-2 (McCullough et al. 2001) and induces expression of pro-apoptotic tribblesrelated protein 3 (TRB3) (Ohoka et al. 2005). Translational attenuation by PERK is transient and countered by several eIF $2 \alpha$ phosphatases. The regulatory subunit of protein phosphatase 1 (PP1), GADD34, is induced late in ER stress by ATF4, and targets PP1 to eIF2 $\alpha$.

Upon BiP release, IRE1 autophosphorylates in trans and activates its endoribonuclease domain (Strudwick and Schröder 2007). Activated IRE1 cleaves exonintron junctions in the mRNAs encoding the bZIP transcription factors homologous to ATF/CREB1 protein (Hac1p) in yeast, HACA in filamentous fungi, and $\mathrm{X}$ box-binding protein 1 (XBP-1)/hepatocarcinogenesis-related transcription factor (HTF)/taxresponsive element binding protein 5 (TREB5) in metazoans (Fig. 4). In yeast, the HACl exons are ligated by transfer RNA ligase. Both transcription factors activate expression of genes encoding ERresident molecular chaperones, protein foldases, and genes encoding proteins involved in ERAD. Hac1 $\mathrm{p}$ and XBP-1 also stimulate phospholipid biosynthesis. 
Spliced Hac1p represses genes under control of the transcriptional regulator unscheduled meiosis 6 protein (Ume6p), including the early meiotic genes and a large array of genes involved in carbon and nitrogen metabolism. This function of spliced Hac1p may explain the slow growth phenotype of yeast cells overexpressing Ire1p or spliced Hac1p (Mori et al. 2000). Attenuation of metabolism by Hac $1 p$ in yeast may substitute for attenuation of general translation by PERK. XBP-1 activation is delayed compared to ATF6 and PERK activation (Yoshida et al. 2003), allowing for an early folding only phase in the UPR followed by a folding and degradation phase. In mammals, phosphorylated IRE1 sequesters tumor necrosis factor receptor associated factor 2 (TRAF2) from pro-caspase 12 , resulting in clustering and activation of this caspase and initiation of apoptosis (Strudwick and Schröder 2007) (Fig. 4). TRAF2 recruits apoptosis signal-regulating kinase 1 (ASK1) and I $\kappa$ B kinase to IRE1. ASK1 activates the mitogen-activated protein (MAP) kinases p38 and ju-nana (jun) $N$-terminal kinases (JNKs). p38 and JNKs phosphorylate and potentiate pro-apoptotic transcription factors, i.e. CHOP and c-Jun, and phosphorylate and inhibit anti-apoptotic Bcl-2 and Bcl- $\mathrm{x}_{\mathrm{L}}$ to induce apoptosis (Szegezdi et al. 2006). Inhibition of JNK phosphatases by ROS formed in oxidative protein folding also contributes to JNK activation (Kamata et al. 2005). Association of the pro-apoptotic Bcl-2 family proteins Bax and Bak with the cytosolic portion of IRE1 is required for efferent IRE1 signaling, i.e. $X B P-1$ mRNA splicing and JNK1 activation (Hetz et al. 2006).

\section{Engineering of the UPR}

Engineering of the UPR holds promise to increase concentrations of several chaperones in a functionally meaningful ratio, thus preventing inadvertent conversion of chaperone foldases into holdases, or even inactivating chaperones because of lack of concomitant increases in co-chaperones and co-factors. The UPR is as much a survival response as it is a response to boost protein secretion. Clearly, some aspects of the physiological UPR are not desirable in an expression system, for example inhibition of general translation by PERK, stimulation of ERAD and apoptosis. Overexpression of spliced Haclp or its filamentous fungi homolog HACA increased heterologous protein secretion in Saccharomyces cerevisiae and Aspergillus niger (Valkonen et al. 2003a, b). In Chinese hamster ovary (CHO)-K1 cells XBP-1 overexpression improved secretion of several heterologous proteins (Ku et al. 2007; Tigges and Fussenegger 2006). In yeast and filamentous fungi, secretion of several heterologous proteins was not improved or even decreased by overexpression of Hac1p (Gasser et al. 2006; Rakestraw and Wittrup 2005; Valkonen et al. 2003a). One drawback of some of these studies is that wild-type (WT) cells with a functional UPR are compared to WT cells overexpressing spliced Haclp, which may explain why in some cases only marginal differences between the two cell types have been observed. The more consistent effect of spliced XBP-1 overexpression on protein secretion ( $\mathrm{Ku}$ et al. 2007; Tigges and Fussenegger 2006) may be caused by a preferential activation of UPR signaling pathways that stimulate cellular functions beneficial for heterologous protein secretion, i.e. increased chaperone gene expression. This increased ER-resident chaperone machinery attenuates all UPR signaling, and most importantly, those UPR signaling pathways likely to decrease protein production, for example general translation inhibition by PERK, stimulation of ERAD and of apoptosis (Özcan et al. 2004).

\section{Conclusions}

Engineering of chaperone systems by overexpressing a single component of the ER-resident protein folding machinery has overall yielded mixed results. Our basic understanding of protein folding in the ER is still incomplete. Addressing these open questions should underpin engineering approaches to improve the performance of chaperone systems. A more detailed understanding of chaperone function and regulation should inform future work to improve chaperone systems. Co-expression of different holdases or targeting of heterologous or cytosolic holdases to the ER may yield more consistent improvements for different heterologous proteins. The function of overexpressed chaperones may not be the same as at their normal physiological concentrations, because of the lack of a corresponding increase in co-chaperones and co-factors. To improve foldase 
function, concomitant elevation of $\mathrm{BiP}$, its co-chaperones, and ATP levels should be attempted.

Engineering of the UPR suggests that mimicking an UPR by expression of its activated signaling molecules does not consistently improve productivities. Dissection of UPR signaling activities may be necessary to improve heterologous protein secretion. To place engineering of the UPR on an informed basis, we need to understand the UPR in more detail. It is still not clear what the most upstream events in activation of the UPR are, how UPR signaling integrates into cellular signaling, and how the UPR decides between a prosurvival and an apoptotic response to ER stress. Cell engineering also needs to address the potential problem that increased oxidative protein folding may be inherently toxic to cells, because of elevated cellular ROS levels.

Acknowledgments Work in my group is currently funded by the BBSRC (BB/C513418/1, BB/D01588X/1, and BB/ E006035/1), the European Commission (MIRG-CT-2005016411), the Wellcome Trust (079821), and travel grants from the BBSRC (ISIS 1754) and Royal Society (CG-2005/R4 and CG-2006/R4).

\section{References}

Alberti S, Esser C, Höhfeld J (2003) BAG-1-a nucleotide exchange factor of $\mathrm{Hsc} 70$ with multiple cellular functions. Cell Stress Chaperones 8:225-231

Butz JA, Niebauer RT, Robinson AS (2003) Co-expression of molecular chaperones does not improve the heterologous expression of mammalian G-protein coupled receptor expression in yeast. Biotechnol Bioeng 84:292-304

Chung JY, Lim SW, Hong YJ, Hwang SO, Lee GM (2004) Effect of doxycycline-regulated calnexin and calreticulin expression on specific thrombopoietin productivity of recombinant Chinese hamster ovary cells. Biotechnol Bioeng 85:539-546

Conesa A, Jeenes D, Archer DB, van den Hondel CAMJJ, Punt PJ (2002) Calnexin overexpression increases manganese peroxidase production in Aspergillus niger. Appl Environ Microbiol 68:846-851

Damasceno LM, Anderson KA, Ritter G, Cregg JM, Old LJ, Batt CA (2006) Cooverexpression of chaperones for enhanced secretion of a single-chain antibody fragment in Pichia pastoris. Appl Microbiol Biotechnol 56:157-164

Dorner AJ, Kaufman RJ (1990) Analysis of synthesis, processing, and secretion of proteins expressed in mammalian cells. Methods Enzymol 185:577-596

Dorner AJ, Wasley LC, Kaufman RJ (1989) Increased synthesis of secreted proteins induces expression of glucoseregulated proteins in butyrate-treated Chinese hamster ovary cells. J Biol Chem 264:20602-20607
Dorner AJ, Wasley LC, Kaufman RJ (1992) Overexpression of GRP78 mitigates stress induction of glucose regulated proteins and blocks secretion of selective proteins in Chinese hamster ovary cells. EMBO J 11:1563-1571

Gasser B, Maurer M, Gach J, Kunert R, Mattanovich D (2006) Engineering of Pichia pastoris for improved production of antibody fragments. Biotechnol Bioeng 94:353-361

Gauss R, Jarosch E, Sommer T, Hirsch C (2006a) A complex of Yos9p and the HRD ligase integrates endoplasmic reticulum quality control into the degradation machinery. Nat Cell Biol 8:849-854

Gauss R, Sommer T, Jarosch E (2006b) The Hrd1p ligase complex forms a linchpin between ER-lumenal substrate selection and Cdc48p recruitment. EMBO J 25:18271835

Gennaro DE, Hoffstein ST, Marks G, Ramos L, Oka MS, Reff ME, Hart TK, Bugelski PJ (1991) Quantitative immunocytochemical staining for recombinant tissue-type plasminogen activator in transfected Chinese hamster ovary cells. Proc Soc Exp Biol Med 198:591-598

Harding HP, Zhang Y, Zeng H, Novoa I, Lu PD, Calfon M, Sadri N, Yun C, Popko B, Paules R, Stojdl DF, Bell JC, Hettmann T, Leiden JM, Ron D (2003) An integrated stress response regulates amino acid metabolism and resistance to oxidative stress. Mol Cell 11:619-633

Hayano T, Hirose M, Kikuchi M (1995) Protein disulfide isomerase mutant lacking its isomerase activity accelerates protein folding in the cell. FEBS Lett 377:505-511

Haynes CM, Titus EA, Cooper AA (2004) Degradation of misfolded proteins prevents ER-derived oxidative stress and cell death. Mol Cell 15:767-776

Hetz CA (2007) ER stress signaling and the BCL-2 family of proteins: from adaptation to irreversible cellular damage. Antioxid Redox Signal (this issue)

Hetz C, Bernasconi P, Fisher J, Lee AH, Bassik MC, Antonsson B, Brandt GS, Iwakoshi NN, Schinzel A, Glimcher LH, Korsmeyer SJ (2006) Proapoptotic BAX and BAK modulate the unfolded protein response by a direct interaction with IRE1 $\alpha$. Science 312:572-576

Höhfeld J, Cyr DM, Patterson C (2001) From the cradle to the grave: molecular chaperones that may choose between folding and degradation. EMBO Rep 2:885-890

Hsu T-A, Betenbaugh MJ (1997) Coexpression of molecular chaperone BiP improves immunoglobulin solubility and IgG secretion from Trichoplusia ni insect cells. Biotechnol Prog 13:96-104

Inan M, Aryasomayajula D, Sinha J, Meagher MM (2006) Enhancement of protein secretion in Pichia pastoris by overexpression of protein disulfide isomerase. Biotechnol Bioeng 93:771-778

Kamata H, Honda S, Maeda S, Chang L, Hirata H, Karin M (2005) Reactive oxygen species promote TNF $\alpha$-induced death and sustained JNK activation by inhibiting MAP kinase phosphatases. Cell 120:649-661

Kato T, Murata T, Usui T, Park EY (2005) Improvement of the production of GFPuv-beta1,3- $N$-acetylglucosaminyltransferase 2 fusion protein using a molecular chaperoneassisted insect-cell-based expression system. Biotechnol Bioeng 89:424-433

Kim M-D, Han K-C, Kang H-A, Rhee S-K, Seo J-H (2003) Coexpression of $\mathrm{BiP}$ increased antithrombotic hirudin 
production in recombinant Saccharomyces cerevisiae. J Biotechnol 101:81-87

Kimata Y, Oikawa D, Shimizu Y, Ishiwata-Kimata Y, Kohno $\mathrm{K}$ (2004) A role for BiP as an adjustor for the endoplasmic reticulum stress-sensing protein Ire1. J Cell Biol 167:445456

Kondo S, Murakami T, Tatsumi K, Ogata M, Kanemoto S, Otori K, Iseki K, Wanaka A, Imaizumi K (2005) OASIS, a CREB/ATF-family member, modulates UPR signalling in astrocytes. Nat Cell Biol 7:186-194

Ku SC, Ng DT, Yap MG, Chao SH (2007) Effects of overexpression of $\mathrm{X}$-box binding protein 1 on recombinant protein production in Chinese hamster ovary and NS0 myeloma cells. Biotechnol Bioeng. doi: 10.1002/bit.21562 (in press)

Lederkremer GZ, Glickman MH (2005) A window of opportunity: timing protein degradation by trimming of sugars and ubiquitins. Trends Biochem Sci 30:297-303

McCullough KD, Martindale JL, Klotz LO, Aw TY, Holbrook NJ (2001) Gadd153 sensitizes cells to endoplasmic reticulum stress by down-regulating $\mathrm{Bcl} 2$ and perturbing the cellular redox state. Mol Cell Biol 21:1249-1259

Mohan C, Park SH, Chung JY, Lee GM (2007) Effect of doxycycline-regulated protein disulfide isomerase expression on the specific productivity of recombinant CHO cells: thrombopoietin and antibody. Biotechnol Bioeng 98(3):611-615

Molinari M, Calanca V, Galli C, Lucca P, Paganetti P (2003) Role of EDEM in the release of misfolded glycoproteins from the calnexin cycle. Science 299:1397-1400

Mori K, Ogawa N, Kawahara T, Yanagi H, Yura T (2000) mRNA splicing-mediated $C$-terminal replacement of transcription factor Haclp is required for efficient activation of the unfolded protein response. Proc Natl Acad Sci USA 97:4660-4665

Oda Y, Hosokawa N, Wada I, Nagata K (2003) EDEM as an acceptor of terminally misfolded glycoproteins released from calnexin. Science 299:1394-1397

Ohoka N, Yoshii S, Hattori T, Onozaki K, Hayashi H (2005) $T R B 3$, a novel ER stress-inducible gene, is induced via ATF4-CHOP pathway and is involved in cell death. EMBO J 24:1243-1255

Oyadomari S, Yun C, Fisher EA, Kreglinger N, Kreibich G, Oyadomari M, Harding HP, Goodman AG, Harant H, Garrison JL, Taunton J, Katze MG, Ron D (2006) Cotranslocational degradation protects the stressed endoplasmic reticulum from protein overload. Cell 126:727-739

Özcan U, Cao Q, Yilmaz E, Lee A-H, Iwakoshi NN, Ozdelen E, Tuncman G, Görgün C, Glimcher LH, Hotamisligil GS (2004) Endoplasmic reticulum stress links obesity, insulin action, and type 2 diabetes. Science 306:457-461

Powers SL, Robinson AS (2007) PDI improves secretion of redox-inactive $\beta$-glucosidase. Biotechnol Prog 23:364369

Rakestraw A, Wittrup KD (2005) Contrasting secretory processing of simultaneously expressed heterologous proteins in Saccharomyces cerevisiae. Biotechnol Bioeng 93:896905

Rosser MF, Trotta BM, Marshall MR, Berwin B, Nicchitta CV (2004) Adenosine nucleotides and the regulation of
GRP94-client protein interactions. Biochemistry 43:88358845

Ruddock LW, Molinari M (2006) $N$-glycan processing in ER quality control. J Cell Sci 119:4373-4380

Schröder M (2007) The cellular response to protein unfolding stress. In: Robson GD, van West P, Gadd GM (eds) Exploitation of fungi. British mycological society symposium series, vol 26. Cambridge University Press, Cambridge, pp 117-139

Schröder M, Friedl P (1997) Overexpression of recombinant human antithrombin III in Chinese hamster ovary cells results in malformation and decreased secretion of the recombinant protein. Biotechnol Bioeng 53:547-559

Schröder M, Kaufman RJ (2005) The mammalian unfolded protein response. Annu Rev Biochem 74:739-789

Schröder M, Körner C, Friedl P (1999) Quantitative analysis of transcription and translation in gene amplified Chinese hamster ovary cells on the basis of a kinetic model. Cytotechnology 29:93-102

Shen JS, Snapp EL, Lippincott-Schwartz J, Prywes R (2005) Stable binding of ATF6 to BiP in the endoplasmic reticulum stress response. Mol Cell Biol 25:921-932

Smith JD, Robinson AS (2002) Overexpression of an archaeal protein in yeast: secretion bottleneck at the ER. Biotechnol Bioeng 79:713-723

Smith JD, Tang BC, Robinson AS (2004) Protein disulfide isomerase, but not binding protein, overexpression enhances secretion of a non-disulfide-bonded protein in yeast. Biotechnol Bioeng 85:340-350

Steel GJ, Fullerton DM, Tyson JR, Stirling CJ (2004) Coordinated activation of Hsp70 chaperones. Science 303:98-101

Strudwick N, Schröder M (2007) The unfolded protein response. In: Al-Rubeai M, Fussenegger M (eds) Systems biology. Cell engineering, vol 5. Springer Verlag, Dordrecht, pp 69-157

Szegezdi E, Logue SE, Gorman AM, Samali A (2006) Mediators of endoplasmic reticulum stress-induced apoptosis. EMBO Rep 7:880-885

Tigges M, Fussenegger M (2006) Xbp1-based engineering of secretory capacity enhances the productivity of Chinese hamster ovary cells. Metab Eng 8:264-272

Tsai B, Rodighiero C, Lencer WI, Rapoport TA (2001) Protein disulfide isomerase acts as a redox-dependent chaperone to unfold cholera toxin. Cell 104:937-948

Tu BP, Weissman JS (2004) Oxidative protein folding in eukaryotes: mechanisms and consequences. J Cell Biol 164:341-346

Vad R, Nafstad E, Dahl LA, Gabrielsen OS (2005) Engineering of a Pichia pastoris expression system for secretion of high amounts of intact human parathyroid hormone. J Biotechnol 116:251-260

Valkonen M, Penttilä M, Saloheimo M (2003a) Effects of inactivation and constitutive expression of the unfoldedprotein response pathway on protein production in the yeast Saccharomyces cerevisiae. Appl Environ Microbiol 69:2065-2072

Valkonen M, Ward M, Wang H, Penttilä M, Saloheimo M (2003b) Improvement of foreign-protein production in Aspergillus niger var. awamori by constitutive induction of the unfolded-protein response. Appl Environ Microbiol 69:6979-6986 
Werner RG (2004) Economic aspects of commercial manufacture of biopharmaceuticals. J Biotechnol 113:171-182

Wilkinson B, Gilbert HF (2004) Protein disulfide isomerase. Biochim Biophys Acta 1699:35-44

Winter J, Jakob U (2004) Beyond transcription-new mechanisms for the regulation of molecular chaperones. Crit Rev Biochem Mol Biol 39:297-317

Wurm FM (2004) Production of recombinant protein therapeutics in cultivated mammalian cells. Nat Biotechnol 22:1393-1398

Yoshida H (2007) ER stress and diseases. FEBS J 274:630-658

Yoshida H, Matsui T, Hosokawa N, Kaufman RJ, Nagata K, Mori K (2003) A time-dependent phase shift in the mammalian unfolded protein response. Dev Cell 4:265271

Zhang K, Shen X, Wu J, Sakaki K, Saunders T, Rutkowski DT, Back SH, Kaufman RJ (2006a) Endoplasmic reticulum stress activates cleavage of CREBH to induce a systemic inflammatory response. Cell 124:587-599

Zhang W, Zhao H-1, Xue C, Xiong X-H, Yao X-Q, Li X-Y, Chen H-P, Liu Z-M (2006b) Enhanced secretion of heterologous proteins in Pichia pastoris following overexpression of Saccharomyces cerevisiae chaperone proteins. Biotechnol Prog 22:1090-1095 